\title{
Expert Systems in Service Operations
}

By: Luvai F. Motiwalla and Vidyaranya B. Gargeya.

Motiwalla, L. F. and Gargeya, V. B. (1992). Expert systems in service operations. Industrial Management \& Data Systems, 92(8), 14-19.

Made available courtesy of Emerald Group Publishing:

http://dx.doi.org/10.1108/02635579210019820

***:C Emerald Group Publishing. Reprinted with permission. No further reproduction is authorized without written permission from Emerald Group Publishing. This version of the document is not the version of record. Figures and/or pictures may be missing from this format of the document. $* * *$

This article is (c) Emerald Group Publishing and permission has been granted for this version to appear here (https://libres.uncg.edu/ir/uncg/). Emerald does not grant permission for this article to be further copied/distributed or hosted elsewhere without the express permission from Emerald Group Publishing Limited.

Abstract:

Despite previous work on expert systems in the manufacturing sector very few articles relate to a classification scheme for the application of Expert Systems (ES) in the service operations area. Based on a review of more than 200 abstracts from the ABI/INFORM database, seeks to provide a categorization of ES in the service sector and also to detail future needs in the application of this vital information technology in service operations. Enhances the manager's understanding of ES technology and provides a perspective on how ES have been used in service operations.

Keywords: Databases | Expert systems | Information management | Information technology | Service industries

\section{Article:}

Several survey, classification and prospect articles have been written on the use of Expert Systems (ES) technology in the manufacturing sector[1,2]. However, very few papers present a classification of the use of ES in the service sector. As the world economy moves to becoming more and more service-oriented, it is expected that ES technology would be utilized extensively in service operations. This article takes a first step by providing a categorization of ES in service operations. This categorization allows the reader to identify service areas where ES are used extensively and areas where more ES need to be developed.

Even though service operations and manufacturing operations appear to be similar on a superficial level, there does exist some difference between the two on more than one dimension[3]. First, a study of the characteristics of service operations reveals that services, compared with manufacturing, are people-oriented. This means that there is not only a greater 
interaction between the employees of the firm and the customers, but there is greater customer participation in the service delivery process. For example, in some restaurants, after placing an order for the entrees, the customers could go over to the salad bar and prepare a salad for themselves. This indicates that customers get actively involved in the service provision. Second, there is simultaneity of service provision and consumption in service operations as compared to manufacturing operations. This indicates that while manufactured products can be inventoried, services cannot be "stocked up" for use at a later point in time. In a service operation, the customers' "consume" the service while it is being provided. Finally, services by default are more intangible than manufactured goods. The intangibility in services leads to unstructured decisionmaking processes, which require the use of a subjective heuristic on the part of the service provider, to solve intangible problems quickly and effectively.

Analogies between services and manufacturing can be superficial and misleading because they tend to ignore the unique, "people-changing" and "people-processing" nature of services[3]. "People-changing" organizations attempt to alter directly the characteristics or behaviour of their customers through the application of various modification and treatment technologies. "Peopleprocessing" organizations, on the other hand, attempt to change their clients, not by altering basic personal attributes, but by conferring upon them a public status and relocating them in a new set of social circumstances. Hence, within this service context, not only is there a need to find new and creative approaches to the study of service operations management, but there is also a need to develop innovative uses of computer-based information systems, for both on-line and off-line operations in services depending upon the nature of services provided. A categorization of all service operations has been provided in Figure 1. This categorization is a modified version of the Fitzsimmons and Sullivan model[3].

\section{Expert Systems and their Importance in Service Operations}

Over the last decade, no other area in information systems has received more attention than ES. ES are a branch of artificial intelligence (AI) that focuses on leveraging the human expertise available within an organization to gain competitive advantage. They do so by capturing the problem-solving know-how of experts, to automate corporate expertise and make it available on a constant basis throughout the organization[4]. The basic philosophy of expert systems has been well represented by Turban[5] as follows:

The basic idea behind ES is simple. Expertise, which is the vast body of task-specific knowledge, is transferred from the human to the computer. This knowledge is then stored in the computer and users call on the computer for specific advice as needed. The computer can make inferences and arrive at a specific conclusion. Then, like a human consultant, it advises the non-experts and explains, if necessary, the logic behind the advice. 


\section{Figure 1. Classification of Services}

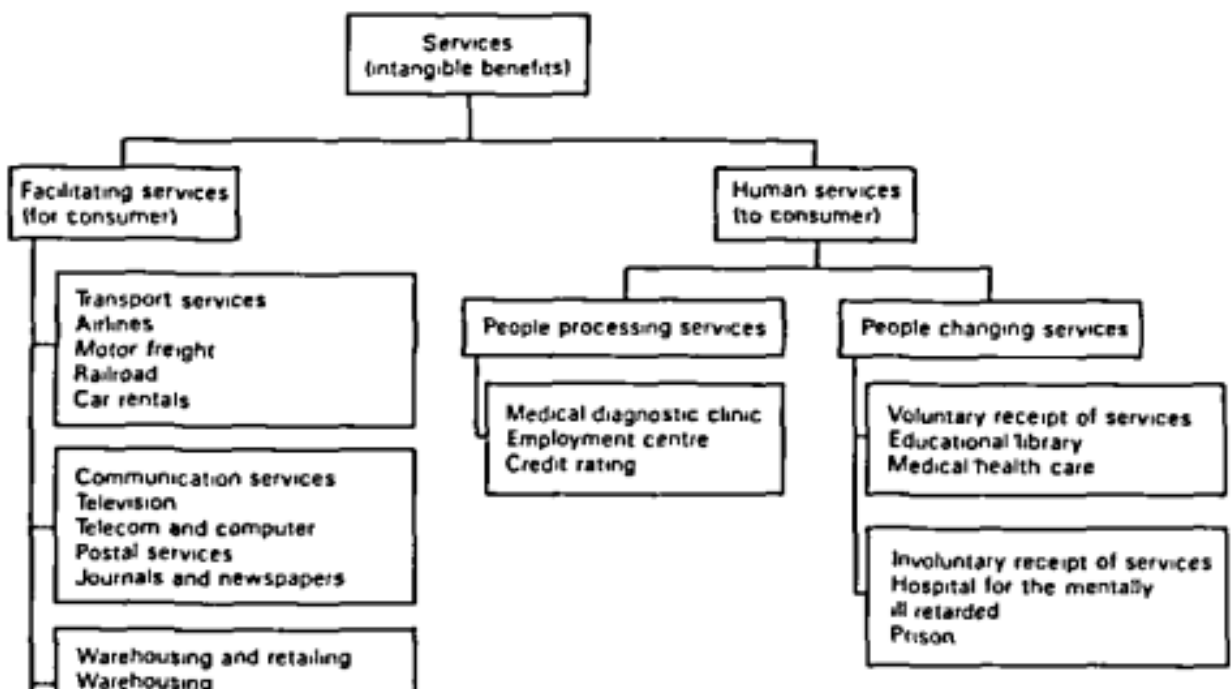

Warehousing

Retailing

Fnancial services

lnsurance

imvestmen

Banking

Accounting and oudt

Accomodation services

Hotel

Restaurant

Games and sporting

Scentific services

RSD

Weather

Legal affaus and governments

Legal affairs

Government

Organizations can use ES to leverage scarce human expertise to improve customer services due to the fact that ES have a portion of the expert's knowledge which can be used to solve welldefined to semi-structured problems in a consistant manner. For example, American Express's expert system (AMEX) for credit approval provides the novice and inexperienced telephone operators with a round-the-clock access to the credit approval knowledge of experienced credit officers[6]. Thus, just as the ATMs provide a 24-hour access to banking services, ES provide a 24-hour access to the expert's knowledge within the organization.

There are several reasons why ES are ideally suited for service operations. First, ES are highly interactive programs. That is, an end-user can demand a must-run explanation or clarification at any time while running an application. This makes ES an ideal technology for most service operations, which are people-oriented, as service consumers or clients play an active role, in terms of providing information and asking questions, in the facilitation of the service. This 
characteristic of ES is ideally suited for the simultaneous provision and consumption component of service operations. For example, the American Express credit-card holder can demand an explanation from AMEX as to why his credit limit was not extended for a credit-card sale. AMEX then displays from its working memory, the heuristic used in the decision-making process. This also helps American Express in training its new operators. Second, ES are much faster in service delivery than their human counterparts. This facet of ES makes them more suitable for services where speed and timeliness are critical to the provision of the service. For example, American Express receives thousands of calls every minute for credit limit extensions, 24-hours a day. Prior to the introduction of the AMEX system, the operator would have to provide customer information to the credit officer on duty and get his/her approval for every call. During peak load hours a customer would have to wait several minutes to get an approval. Now, with the AMEX system installed on every operator's terminal, the response time has been reduced to a matter of seconds. Third, ES do not fatigue and hence can provide consistent and round-the-clock service to service providers and consumers. For example, AMEX can operate consistently at any hour of the day without taking any breaks. Finally, ES use knowledge of the best "experts" in the organization and hence ES guarantee the best quality service to clients all the time. For example, AMEX uses credit approval knowledge of the best loan officers, not just any loan officer.

The above-mentioned reasons suggest that there is as much need, if not more, for the use of ES in the decision-making process of service operations as in manufacturing operations. Since there is a greater degree of subjectivity and intangibility in service operations (as compared to manufacturing operations), it is all the more essential that important decision-making tools such as ES be made use of in service operations. There is not only a great deal of subjectivity in the decision-making process of the service provider, but there is an enormous amount of subjectivity and naivety on the part of the service consumer. This aspect of the service sector underscores the fact that the ES could be extremely useful in the decision-making process of both the service provider and the service consumer. The service-providing company can disseminate enhanced decision-making skills right down to the level of the customer. This is due to the fact that expert's knowledge can be easily duplicated and distributed through an ES to all employees who are involved in directly serving the customer. For example, Toyota Motors service department has an ES which can be accessed by all its service centres for diagnosing car-care problems[6]. This ensures best quality, consistent and friendly service on the part of the provider. ES also benefit the service consumer because the consumers can seek answers from the ES to, what the consumers may consider, even apparently naive questions without being concerned about embarrassing themselves and at the same time receive consistent explanations of how and why the system made a certain recommendation. These explanations can serve as a training (peoplechanging) device for the naive consumer in areas such as auto repairs and home improvement where a consumer has to keep up with the new tools and technologies.

Quite similar to manufacturing operations, the decision-making process in service operations also involves a wide variety of criteria, and the decisions tend to be "fuzzy" or based on intuition[3]. Thus, there is a greater requirement for developing ES based on heuristic rather than optimizing algorithms to solve problems in service operations. The usage of the latter process no doubt would enable the system to come up with more accurate decisions but would entail the development and processing of data based on a large number of criteria and constraints. The 
development and processing of information based on a large number of criteria and constraints may not be feasible due to the "fuzzy" nature of the problem-solving processes in service operations.

\section{Categorization of Expert Systems in Service Operations}

In the past few years, several articles have been written on the use of ES in various serviceoriented organizations. The use of ES in services can be classified on the basis of the specific area of application within the service sector. Service operations management applications of ES presented in articles catalogued in published sources[6,7,8], and abstracts of articles listed in ABI/INFORM (a CDROM library search facility from UMI Corporation), have been categorized using the framework shown in Figure 1. The published sources provide a list of ES applications before 1986 while the ABI/INFORM source provides a list of ES applications from 1986 to 1990. As the number of sources from which the list of EX applications has been generated is limited, it is acknowledged by the authors that this categorization may not include all the ES applications in service operations. However, it is the belief of the authors that this categorization is representative of the total population of ES applications in service operations. In all over 200 articles of ES applications were reviewed from both the sources. A brief outline of the categorization is presented in Table I. A general description of the findings from this categorization is presented in the remainder of this section.

\section{Transport Services}

Transport services, which constitute one of the important sectors of the economy, include services related to air, road, rail and sea transport. There are several engineering applications of ES (such as engine vibration diagnosis) in the transport industry. However, there are no applications of ES that relate to the supply of transport services to consumers from a managerial/business standpoint. There are a few ES in airline, motor freight, and car rental agencies, but no ES were found in the shipping and railroad industries.

\section{Communication Services}

In recent years, communication services have been fast developing into a vital sector of the service economy. The communications industry includes television services, telecommunications and computer services, postal services, and news media services. ES have been extensively used in the telecommunications and computer services, postal services and news media services but no ES were found in television services.

\section{Warehousing and Retailing Services}

Warehousing and retailing services constitute a vital link between the manufacturers and the consumers. Value is added by the warehousing and retailing firms through the process of storage and exchange. In recent years, a few ES have been developed in the retailing industry, but no ES were found in the warehousing industry.

\section{Financial Services}


One of the most popular sectors of the service economy where ES have been developed extensively is in insurance, finance, banking and accounting. Three noteworthy knowledge systems under development for mainframe use include: (1) the Charge Card Approval knowledge system from American Express Co., (2) Financial Product Advisor from the Travelers Corporation, and (3) the Lending Advisor from Syntelligence Inc.[9]. Nearly 25 per cent of the nation's 100 leading insurance companies surveyed by Coopers \& Lybrand are now using ES. The survey also showed that 65 per cent of the firms are involved in some way with ES. The study revealed that some 70 per cent of life and health insurance companies are involved in ES technology as compared to 56 per cent of their property-casualty counterparts[10]. Most ES applications in the insurance industry are custom-designed. Some in the field predict that some time in the future, off-the-shelf systems will be available[11]. Over the next decade, ES are expected to be applied to virtually all the areas of life insurance information services which require expert knowledge and decision making.

The growth of ES technology in banking services has been slow, and most bankers seem to be reluctant to embrace it fully. One of the major reasons for the sluggish growth of ES technology in banking applications is a shortage of mentors or bankers to teach their skills to computers [12]. One other reason is that the research and development efforts and test runs are taking much longer than had been anticipated. It has been reported that banks in the UK are also slowly developing ES for dealing room applications such as: (1) spotting arbitrage opportunities; (2) hedging block equity trading; and (3) predicting price movements[13]. It has been predicted that, by 1993, about 80 per cent of all banks will be using ES in some form[14]. Some banks have started to use small-scale ES to enhance the credit analysis and loan review processes[15]. 
Table I. A Categorization of ES Applications in Service Operations

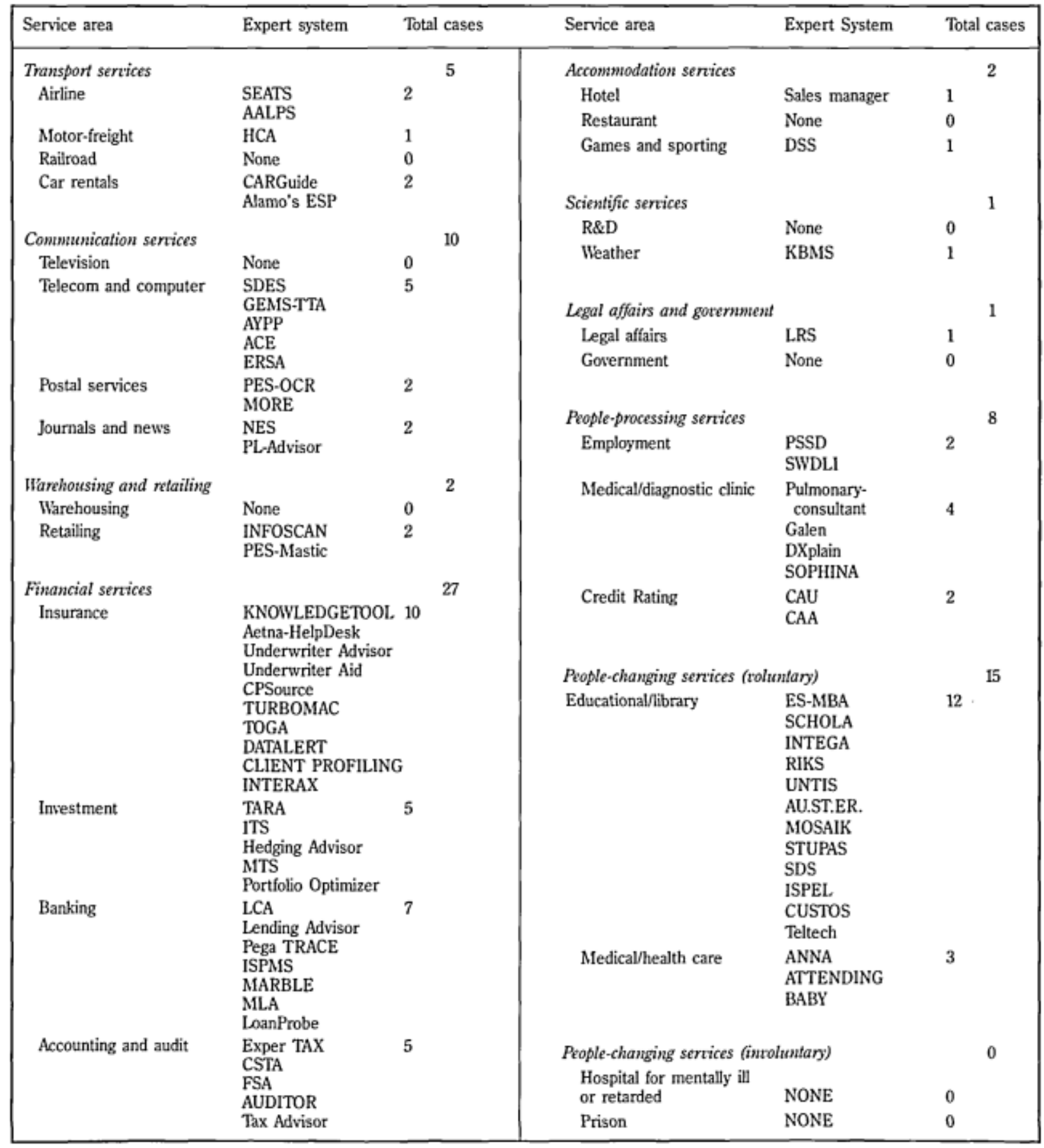

\section{Accommodation Services}

Accommodation services provide physical (in most cases) and psychological (in some cases) comfort to customers. Some of the important service organizations which fall under this category are hotels and restaurants. While ES have found their way into hotel services, none have been identified in the restaurant services. As people tend to have more and more time devoted to games and sporting events, this sector of society has no limits in terms of growth and potential. 
The games and sporting industry includes a variety of organizations ranging from ski resorts to sporting event franchises. It has been noted that ES were developed to schedule events to meet a multi-criteria objective at the 1992 Barcelona Summer Olympic Games [16]

\section{Scientific Services}

Organizations that offer scientific services vary from research and development establishments to weather bureaus. ES are being developed for application in these organizations as well. ES have been developed in a large UK industrial research and development establishment to prioritize the projects to allocate the scarce resources[17]. Due to the fact that the prediction of the weather is an inexact science, several weather bureaus are considering the use of ES technology in their operations.

\section{Legal Affairs and Government}

In recent times, a large amount of computerization has been undertaken in government organizations. With this, it is very well expected that the next step would be the development and usage of ES in the functioning of the government. A few ES are being considered in the legal affairs area, but none have been found in government offices.

\section{People-processing Services}

As stated in an earlier section above, people-processing services attempt to change their clients by conferring upon them a public status and relocating them into a new set of social circumstances. Services that are included under this category are employment services, creditrating services, and medical diagnostic services. While there are only a few ES in employment services, and credit-rating services, there are many ES in medical services. In fact, the medical services area has been one of the pioneering areas for ES. MYCIN was one of the first commercially used ES to diagnose patients with bacteraemia, meningitis and cystitis infections. There are 43 ES developed and commercially used in diagnostic services[7]. A few have been listed to give the reader a flavour of the kinds of ES in this area.

\section{People-changing Services}

As stated in an earlier section, people-changing services attempt to alter directly the attributes or behaviour of their clients through the application of various modification and treatment technologies. Services that fall under this category could be sought by customers on a voluntary, or an involuntary basis.

In voluntary receipt, people-changing services, services are sought by the clients of their own volition. Services that fall under this category are educational/library services, and health/medical services. There are a few ES being developed in the educational/library services and at least ten ES have been identified in the health/medical services[7].

On the other hand, the involuntary, receipt peoplechanging services are services that are sought by the customers on an involuntary basis, that is, they are not sought by the clients of their own 
volition, but are provided to them by society for their wellbeing. Services that fall under this category are services provided by the hospital for the mentally ill/retarded and prisons. ES have not been developed in this area.

\section{Conclusions}

This article has presented a categorization of the applications of ES in service operations management. It should be noted, however, that the above categorization does not represent an exhaustive list of ES applied to service operations. The authors acknowledge that several applications of ES may have been omitted in this categorization, due to any one or a combination of following reasons. Some of the applications of ES may be:

(1) not reported as ES but rather as decision support systems, etc;

(2) proprietary in nature and hence might not have been reported publicly;

(3) in the prototype stage and may not have been fully tested and implemented and therefore not reported.

Despite the above limitations, this categorization serves as a basis for examining and comparing the ES applications in the service sector. This categorization can be used to identify new application opportunities for ES in service operations management. The categorization of ES in service operations indicates that in some areas of the service economy there is an abundance of ES applications. Some of those areas are telecommunication and computer services, finance, banking and insurance services, and medical services (both diagnostic and health care provision). On the other hand, very little has been done in applying ES in the areas of railroad, shipping, television and people-changing involuntary services, such as health services for the mentally ill or retarded, and prison services. It is quite likely that the above-mentioned sectors of the service economy may not be suitable for the application of ES. It is suggested that future research should focus on understanding the reasons for non-development of ES in these sectors of the economy.

The categorization carried out here may turn out to be beneficial to service operations managers and ES specialists in more ways than one. First, this categorization helps service operations managers (in a specific sector of the economy) to identify the kinds of ES applications that have been developed in their area of interest. Second, using this categorization, ES specialists can identify opportunities for developing ES applications. Last of all, operations managers involved with a particular type of service could consider adopting ES applied in a different sector of the economy.

\section{References}

1. Mertens, P. and Kanet, J.J., "Expert Systems in Production Operations: An Assessment", Journal of Operations Management, Vol. 6 No. 4, 1986, pp. 393-404.

2. Rao, H.R. and Lingaraj, B.P., "Expert Systems in Production and Operations Management: Classification and Prospects", Interfaces, Vol. 18 No. 6, 1988, pp. 80-91. 
3. Fitzsimmons, J.A. and Sullivan, R.S., Service Operations Management, McGraw-Hill, New York, NY, 1982.

4. Peppard, J., "Corporate Knowledge-Based Systems: Implication and Impact", Management Decision, Vol. 27 No. 5, 1989, pp. 48-52.

5. Turban, E., Decision Support and Expert Systems Managerial Perspectives, Macmillan, New York, NY, 1990.

6. Feiganbaum, E., McCorduck, N. and Nii, L., The Rise of Expert Company, Times-Mirror, New York, NY, 1989.

7. Waterman, D.A., A Guide to Expert Systems, AddisonWesley, Reading, MA, 1986.

8. Harmon, P., Maus, R. and Morrissey, W., Expert Systems: Tools \& Applications, John Wiley \& Sons, New York, NY, 1988.

9. Vacca, J.R., "The Birth of Banking's Knowledge Systems", Banking Software Review, Vol. 12 No. 4, 1987, pp. 68-71.

10. Haggerty, A.G., "Future is Now for Washington WC Insurer", National Underwriter (Property/Casualty/ Employee Benefits), Vol. 92 No. 31, 1988, p. 15.1

1. Benham, B.T., "The Promise of Technology", Best's Review (Property/Casualty), Vol. 88 No. 7, 1987, pp. 40-6, 121.

12. Fitch, T.P., "Teaching Computers to be Bankers", Bankers Monthly, Vol. 105 No. 5, 1988, pp. 51-4.

13. Kanji, S., "When is an Expert not an Expert?", Banker (UK), Vol. 138 No. 746, 1988, pp. 868.

14. Belser, M.F., "Expert Systems put Expertise in Everyone's Hands", Financial Managers' Statement, Vol. 10. No. 5, 1988, pp. 43-5. 15. McGinn, C., "Computer Mentors give Loan Officers a Hand", ABA Banking Journal, Vol. 82 No. 11, 1990, pp. 45-53.

16. Andreu, R. and Corominas, A., "SUCCES92: A DES for Scheduling the Olympic Games", Interfaces, Vol. 19 No. 5, 1989, pp. 1-12.

17. Grainge, N.J. and Pearson, A.W., "Managing an In-House R\&D Service Department", R\&D Management (UK), Vol. 19 No. 1, 1989, pp. 27-45. 